Canadian

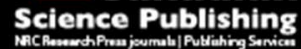

Canadian Journal of Microbiology Revue canadienne de de microbiologie

\title{
A fast and accurate method of detecting Aleutian mink disease virus in blood and tissues of chronically infected mink
}

\begin{tabular}{|r|l|}
\hline Journal: & Canadian Journal of Microbiology \\
\hline Manuscript ID & cjm-2016-0567.R2 \\
\hline Manuscript Type: & Article \\
\hline Date Submitted by the Author: & 10 -Jan-2017 \\
\hline Complete List of Authors: & $\begin{array}{l}\text { Farid, A. H.; Dalhousie University Faculty of Agriculture, Animal Science } \\
\text { Rupasinghe, Priyanka; Dalhousie University Faculty of Agriculture, Animal } \\
\text { Science }\end{array}$ \\
\hline Keyword: & $\begin{array}{l}\text { Aleutian mink disease virus, Polymerase chain reaction, Viral DNA } \\
\text { detection, Omni Klentaq-LA, Dynabeads Silane }\end{array}$ \\
\hline
\end{tabular}

\section{SCHOLARONE"}

Manuscripts 
A fast and accurate method of detecting Aleutian mink disease virus in blood and tissues of chronically infected mink

A.H. Farid* and P.P. Rupasinghe

Department of Animal Science, Dalhousie University Faculty of Agriculture, Truro, Nova Scotia, B2N 5E3, Canada

ah.farid@dal.ca

prupasinghe@dal.ca

*Corresponding author, Tel. 001-902-893-6727, fax number 001-902-896-6734, e-mail address: ah.farid@dal.ca 


\section{Abstract}

The objective of this study was to assess sensitivity of the Omni Klentaq-LA DNA polymerase for detecting Aleutian mink disease virus (AMDV) in mink blood and tissues by PCR without DNA extraction. The presence of AMDV DNA was directly tested by Klentaq in plasma, serum, whole blood and spleen homogenates of 188 mink 4 and 16 months after inoculation with the virus. Samples from bone marrow, small intestine, liver, lungs, kidneys and lymph nodes of 20 of the same mink were also tested by Klentaq. DNA was extracted from paired samples of plasma and the aforesaid tissues by a commercial nucleic acid extraction kit (Dynabeads Silane) and tested by PCR. Compared with the extracted DNA, Klentaq detected a significantly greater number of samples in the whole blood, serum, plasma, spleen and small intestine. It was concluded that Klentaq is a preferred system for directly detecting AMDV DNA in mink blood and tissues. The lower success rate of extracted DNA compared with Klentaq could be the result of DNA losses during the extraction process. This is an important factor in chronically infected mink which have a low AMDV copy number in the bloodstream. Direct AMDV detection also reduces the cost of PCR amplification and lowers the risk of sample contamination.

Keywords: Aleutian mink disease virus; Polymerase chain reaction; Viral DNA detection; Omni Klentaq-LA; Dynabeads Silane 


\section{Introduction}

Aleutian mink disease virus (AMDV, Carnivore amdoparvovirus 1), a species of the genus Amdoparvovirus, family Parvoviridae (Cotmore et al. 2014), exists in almost all mink producing countries. The virus causes Aleutian disease, an immune-complex syndrome (reviewed in Bloom et al. 1994), leading to reduced reproductive performance (Broll and Alexandersen 1996; Reichert and Kostro 2014) and increased adult and kit mortality (Bloom et al. 1994; Dyer et al. 2000). With no effective vaccine (Aasted et al. 1998; Castelruiz et al. 2005) or cure, testing animals by counter-immunoelectrophoresis (CIEP) (Cho and Ingram 1973) and removal of sero-converted individuals has been the preferred method of controlling AMDV globally, but this strategy has shown limited success in many counties, including Canada (Farid et al. 2012). One reason for the failure of test and kill strategy is false negative CIEP test results during the early stages of infection (Bloom et al. 1975; Hadlow et al. 1985, Farid et al. 2015). PCR, on the contrary, can detect infection earlier than CIEP (Jackson et al. 1992; Oie et al. 1996; Farid et al. 2015), which is important when an AMDV-free ranch becomes infected and animals that carry the virus ought to be identified and eliminated as fast as possible. PCR, however, fails to detect the virus in some chronically infected mink when virus replication becomes restricted (Jackson et al. 1996; Jensen et al. 2014).

PCR is not widely used by mink ranchers for routine herd screening, primarily because of its high cost, which is partly associated with the DNA extraction step needed to remove inhibitors in biological materials (Reviewed in Rådström et al. 2004; Alaeddini 2012). DNA extraction methods, including commercial kits, may leave behind some residual inhibitors and often result in loss of sample DNA (Shipley et al. 2012; Monroe et 
al. 2013; Barta et al. 2014; Kemp et al. 2014), and increase the chance of sample crosscontamination (Frickhofen and Young 1991; Queipo-Ortuño et al. 2008).

Attempts have been made to eliminate the DNA extraction step from blood and other biological samples to reduce the cost of PCR tests, reduce DNA losses and lower the risk of sample contamination (Rådström et al. 2004; Yang et al. 2007; Trombley Hall et al. 2013). PCR inhibitors affect the activity of DNA polymerase enzymes (Rådström et al. 2004; Eilert and Foran, 2009; Monroe et al. 2013) and there are differences among enzymes in their ability to directly amplify DNA in blood by PCR (Abu Al-Soud and Rådström 1998; Miura et al. 2013). The Omni Klentaq is a Taq DNA polymerase lacking 278 amino acids in its $\mathrm{N}$-terminal region (Klentaq 1 ) and contains a glutamic acid to lysine substitution at codon 708 , which confers resistance to several PCR inhibitors (Kermekchiev et al. 2009) and can directly amplify target DNA from samples containing as much as $25 \%$ whole blood, plasma and serum when used with the inhibitor-resistant PCR Enhancer Cocktail (Zhang et al. 2010). The objective of this study was to assess the sensitivity of direct AMDV DNA detection in the whole blood, serum, plasma and various organs of mink by the Klentaq, using DNA extracted by a commercial kit (Dynabeads Silane) as the control.

\section{Materials and Methods}

The statement of animal care

All protocols were performed according to the standards of the Canadian Council on Animal Care after approval by the institutional Animal Care and Use Committee (File number 2009-015). Animals were maintained in an enclosed facility (Aleutian Disease 
Research Centre) according to the standard industry practices in $61.0 \times 30.5 \times 20.3 \mathrm{~cm}$ cages. Prior to inoculation or blood sampling, animals were anesthetized by intramuscular injection of ketamine hydrochloride (Ketalean, Bimeda-MTC Cambridge, ON, Canada) and xylazine hydrochloride (Rompun 2\%, Bayer Health Care) at the rates of $10 \mathrm{mg}$ and $2 \mathrm{mg}$ per kg live weight, respectively. Animals were anesthetized prior to being euthanized by intracardiac injection of sodium pentobarbital (Euthanyl, Bimedia-MTC) at the rate of 100 mg per kg body weight or occasionally by $\mathrm{CO}_{2}$ inhalation in a wooden box.

\section{$\underline{\text { Source of tissues }}$}

Black American mink (Neovison vison) which were intranasally inoculated in the fall of 2010 or 2011 with $600 I_{50}$ of a spleen homogenate containing a local strain of AMDV (Farid et al. 2015) were used in this study. Animals were euthanized approximately 4 and 16 months post-inoculation in January or February of 2012. Blood was collected by heart puncture into heparinized tubes for plasma preparation for the CIEP test, in EDTA-coated tubes for viral detection by PCR, and in plain tubes for serum preparation. Blood samples were kept in a refrigerator overnight and centrifuged at $1397 \mathrm{~g}$ (Porta Spin C826 centrifuge, Unico, Dayton, NJ, USA) for 10 min for serum and plasma preparation. After pelting, samples from seven organs (bone marrow, spleen, lymph nodes, liver, kidneys, small intestine (duodenum) and lungs) were harvested and transferred into cryovials. All blood and tissue samples were stored at $-80^{\circ} \mathrm{C}$ until use. Sample preparation was performed at the bio-secure laboratory (Level II) following approved Standard Operating Procedures. Animals which were used in this study were all tested positive for antibodies against the virus when euthanized and tested by CIEP as previously described (Farid et 
al., 2015).

\section{Laboratory procedures}

Cell-free tissue preparation

Tissue homogenates were prepared by cutting approximately $0.25 \mathrm{~g}$ of frozen tissue into small pieces with sterile scissors, $50 \mu \mathrm{L}$ of sterile phosphate buffered saline (PBS, Sigma-Aldrich, St. Louis, MO, USA) was added and homogenized with a batteryoperated Kontes grinder (VWR, Mississauga, ON) until it became a uniform paste. Another $700 \mu \mathrm{L}$ of cold PBS was added, the mixture was briefly vortexed and centrifuged at 16,000 $\times \mathrm{g}$ (Eppendorf 5415C, Hamburg, HH, Germany) for $10 \mathrm{~min}$, and the supernatant was saved for analysis.

Direct AMDV DNA amplification using Klentaq

Direct AMDV amplification was performed by PCR in $25 \mu \mathrm{L}$ total volumes containing (final concentration) 1X PCR buffer, $0.2 \mathrm{mM}$ each dNTP, $400 \mathrm{nM}$ each primer, 1X (12.5 $\mu \mathrm{L}$ ) PCR Enhancer Cocktail (PEC-2) and $0.25 \mu \mathrm{L}$ of Omni Klentaq-LA, both supplied by the DNA Polymerase Technology (http://www.klentaq.com). The primer pair was 60F/60R as previously described (Farid, 2013). Three PCR tests were performed on each sample using $0.5,1.0$ and $2.0 \mu \mathrm{L}$ of tissue homogenates, plasma, serum and whole blood diluted three times with nuclease-free water (Qiagen, Mississauga, ON). The thermal cycler (BioRad C1000 or $\mathrm{S} 1000$ series) was programmed at an initial denaturation at $95^{\circ} \mathrm{C}$ for 5 min, followed by 34 cycles of denaturation at $94^{\circ} \mathrm{C}$ for $30 \mathrm{~s}$, annealing at $58.0^{\circ} \mathrm{C}$ for $30 \mathrm{~s}$, extension at $72^{\circ} \mathrm{C}$ for $60 \mathrm{~s}$ and a final extension at $72^{\circ} \mathrm{C}$ for $6 \mathrm{~min}$. 


\section{PCR amplification of extracted DNA}

DNA was extracted from $200 \mu \mathrm{L}$ of plasma and tissue homogenates by Dynabeads Silane (DB) viral nucleic acids extraction kit according to the manufacturer's protocol (Invitrogen, Burlington, ON), and eluted in $100 \mu \mathrm{L}$ elution buffer. The extracted DNA was amplified by PCR using primers $60 \mathrm{~F} / 60 \mathrm{R}$ in $15 \mu \mathrm{L}$ total volumes containing (final concentrations) $0.1 \%$ Tween 20, 1 X PCR buffer, $0.2 \mathrm{mM}$ each dNTPs (Roche), $400 \mathrm{nM}$ each primer, $1.5 \mathrm{mM} \mathrm{MgCl}_{2}$ and 0.8 units of Taq polymerase (Invitrogen, Burlington, $\mathrm{ON}$ ). Three PCR tests were performed on each sample using 1.5, 2.5 and $3.5 \mu \mathrm{L}$ of extracted DNA, and the thermal cycler was programmed as explained above for direct PCR amplification.

PCR products were run on agarose gels (Agarose 1, Mandel Scientific, Guelph, ON) and stained with ethidium bromide. A sample was considered positive when at least one of the PCR reactions showed a strong amplification or at least two of the reactions produced faint bands. The reaction was considered inconclusive when only one of the reactions resulted in a faint amplification. All PCR tests included a reaction containing DNA from a known AMDV-infected mink (positive control for extracted DNA) or plasma from an AMDV-infected mink (positive control for the Klentaq) and a blank reaction (negative control). Sample preparation, DNA extraction, PCR amplification and PCR product testing were performed in four different laboratories in two buildings with unidirectional sample movement to avoid cross-contamination. Sterile filtered-tips were used throughout the experiment. Specificity of the Klentag PCR products was confirmed by sequencing of five samples. 
DATA analysis: The Likelihood Ratio Chi-square test in the SAS program, V9.2, was used to compare PCR results of direct viral detection by the Klentaq and extracted DNA, and for comparing PCR results of direct amplification of plasma, serum and whole blood. Positive, inconclusive and negative PCR results tested by the Klentaq method were scored as 1.0, 0.5 and 0.0 , respectively, and the effect of sample volume was compared using the nonparametric Kruskal-Wallis ANOVA. In cases where the ANOVA showed significant differences at $\alpha=0.05 \%$ level, pairwise comparisons between sample volumes were made by Mann-Whitney test after the Bonferroni correction for multiple comparisons.

\section{$\underline{\text { Results }}$}

\section{Optimization of direct AMDV DNA amplification conditions using Klentaq}

Undiluted whole blood often resulted in gelling of the PCR mixture during the amplification process and caused reaction failure, which could be the result of initial heating of PCR cocktails at $94^{\circ} \mathrm{C}$ for 10 min (Frickhofen and Young 1991). Serial dilution of whole blood samples with nuclease-free water at the rates of 1:0, 1:1, 1:2, 1:3 (Vol:Vol), showed the highest PCR success rate at 1:3 dilution. Lower dilutions resulted in gelling of the PCR mixture during the amplification process in some samples and higher dilutions were not tested to avoid PCR failure because of low virus copy number. Using $4.0 \mu \mathrm{L}$ and $5.7 \mu \mathrm{L}$ of 1:3 diluted whole blood also reduced the rate of PCR success.

The Klentaq supplier's suggestion of $94^{\circ} \mathrm{C}$ initial denaturation for $10 \mathrm{~min}$, followed by 30 cycles of $94^{\circ} \mathrm{C}$ denaturation for $50 \mathrm{~s}, 56.4^{\circ} \mathrm{C}$ annealing for $50 \mathrm{~s}$ and $68^{\circ} \mathrm{C}$ extension for $60 \mathrm{~s}$ for the thermal cycler was initially followed. The optimized amplification conditions used in this study resulted in $72.2 \%$ success rate for plasma compared with $53.8 \%$ for the 
Company's suggested program $\left(n=36, \varkappa^{2}=14.8, P<0.001\right)$. The corresponding values for serum samples were $52.0 \%$ and $25.3 \%\left(n=75, \varkappa^{2}=8.20, P=0.08\right)$ and for spleen homogenates were $73.4 \%$ and $51.1 \%\left(n=188, \varkappa^{2}=88.4, P=<0.001\right)$.

Comparison between direct viral DNA detection in the whole blood, plasma and serum and extracted DNA

The joint distributions of PCR results of extracted DNA from plasma by DB and direct amplification of AMDV DNA in the whole blood, plasma and serum of the 188 mink by the Klentaq are shown in Table 1. Results were significantly different $(P<0.001)$ between the two PCR methods for the three types of blood preparations. Of the 91 plasma samples that were positive using the Klentaq, only $16(17 \%)$ were positive using the DB method and $4(4.3 \%)$ were inconclusive. The 19 samples that were inconclusive using the Klentaq method, all were negative using the DB method. Of the 77 plasma samples that were negative using the Klentaq, $76(98 \%)$ were also negative using the DB and one was inconclusive. Of the 79 serum samples that were positive using the Klentaq,15 (19\%) were positive using the DB method and $4(5.1 \%)$ were inconclusive. Of the 15 samples that were inconclusive using the Klentaq, 14 were negative and one (6.7\%) was inconclusive using the DB method. Of the 94 samples that were negative using the Klentaq, 93 (98.9\%) were negative using the DB and one was positive. Of the 65 whole blood samples that were positive using the Klentaq, $16(24.6 \%)$ were positive using the DB method and 2 (3.1\%) were inconclusive. Of the 38 samples that were inconclusive using the Klentaq, 37 were negative and one (2.6\%) was inconclusive using the DB method. Of the 85 samples that were negative using the Klentaq, $83(97.6 \%)$ were negative using the DB with two 
being inconclusive. Although samples were all from inoculated mink which were CIEP positive, neither of the PCR methods detected AMDV DNA in 76 (40.6\%), 93 (49.4\%) and $83(44.1 \%)$ of the plasma, serum and whole blood samples, respectively.

Pairwise comparisons of PCR results of direct amplification of AMDV DNA by the Klentaq in the three blood preparations of the 188 samples showed that plasma was significantly different from serum and whole blood, but the results of serum and whole blood were comparable (Table 2). The largest number of positive PCR results were observed in plasma $(n=91,48.4 \%)$ followed by serum $(n=79,42.0 \%)$ and whole blood $(n=65,34.6 \%)$, and the largest number of inconclusive tests was in whole blood $(20.2 \%)$ followed by plasma $(10.1 \%)$ and serum $(8.0 \%)$. Consequently, the largest number of negative PCR results were observed in serum (50.0\%), followed by whole blood $(44.6 \%)$ and plasma (41.0\%), suggesting that plasma was the best blood preparation method for the direct detection of AMDV DNA by the Klentaq.

\section{Comparison between direct viral DNA detection and extracted DNA from tissues}

PCR results were significantly different between the direct amplification by the Klentaq and extracted DNA by DB for spleen, small intestine, kidneys and liver samples, approached significance $(P=0.06)$ for the lungs and were comparable for bone marrow and lymph node samples (Table 3). Samples which were PCR positive by DB were $100 \%$ positive by the Klentaq in bone marrow, small intestine, liver and lungs, $94.0 \%$ positive in spleen, $92.3 \%$ positive in kidneys and $86.7 \%$ positive in lymph nodes. On the contrary, a small number of samples which were PCR positive by DB became negative by the Klentaq, including 2 of 83 spleens (2.4\%), 1 of 13 kidneys (7.7\%) and 1 of 15 lymph nodes 
$(6.7 \%)$.

A larger number of samples which were PCR negative in extracted DNA by DB became positive by the Klentaq, including 47 of 92 spleens (51.1\%), 2 of 3 bone marrows $(66.7 \%), 6$ of 13 small intestines (46.2\%), 1 of 7 kidneys (14.3\%) and 9 of 12 lung samples (75.0\%). Except for spleen and bone marrow, there were no inconclusive results for extracted DNA in the tissues. Between zero (lymph node and lungs) and 33.3\% (bone marrow) samples which were negative by DB became inconclusive by the Klentaq. The results suggested that the type of organ influenced the chance of PCR success by direct amplification by the Klentaq and by DB, and that the Klentaq significantly increased the chance of PCR success for spleen, small intestine and lung samples. The number of samples which were PCR negative by both PCR methods were zero (bone marrow), 6.25\% (lymph node), $15.0 \%$ (lungs), $17.0 \%$ (spleen), $25.0 \%$ (small intestine, kidneys) and $40 \%$ (liver).

\section{Sample volume:}

Percentages of positive and inconclusive PCR results in direct amplification by the Klentaq were comparable in $0.5 \mu \mathrm{L}$ and $1.0 \mu \mathrm{L}$ input volumes in plasma and serum, but increased considerably when $2.0 \mu \mathrm{L}$ volumes were used (Table 4), which resulted in a significant difference for the combined positive and inconclusive PCR results between 2.0 $\mu \mathrm{L}$ and 0.5 and $1.0 \mu \mathrm{L}$ sample volumes. Percentages of PCR positive results were comparable in the three sample volumes for the whole blood, but percentage of inconclusive PCR results increased steadily as whole blood input volume increased (Table 
4), resulted in a significantly lower success rate of $0.5 \mu \mathrm{L}$ sample volume than 1.0 and 2.0 $\mu \mathrm{L}$. Sample volume did not significantly affect PCR success rate for spleen homogenate.

\section{Discussion}

Blood is the most commonly used material for molecular diagnosis in humans and live animals because of its ease of collection and processing. Serum (Oie et al. 1996), plasma (Jensen et al. 2014; Farid et al. 2015) and leukocytes (Jackson et al. 1992, 1996) have been used for the detection of AMDV DNA in mink, but there is no published report comparing the PCR success rate of various blood fractions for parvoviruses. Although not very pertinent to parvoviruses, the success of detecting DNA viruses or measuring viral load by PCR in human blood fractions is still subject to controversy. It was shown that DNA extracted from whole blood was more representative of Epstein-Barr virus burden in human circulation than serum or plasma (Stevens et al. 2001). In humans, DNA extracted from leukocytes provided larger number of PCR positive results than those extracted from plasma for detection of Epstein-Barr virus (Ito et al. 2016) and cytomegalovirus (Deback et al. 2007; Chen 2014). In two groups of humans, a larger number of samples were tested positive for herpes virus-6 DNA by PCR using DNA extracted from blood mononuclear cells $(66.7 \%$ and $41.46 \%)$ compared with serum (60.3\% and $14.6 \%)$, but the amounts of DNA (copies/mL) were lower in blood cells (165 and 157) than in plasma (264 and 192) (Ramroodi et al. 2013). On the contrary, 18.8\% of samples were PCR positive for EpsteinBarr virus in DNA extracted from blood cells, whereas $43.8 \%$ of the same group were PCR positive for the viral DNA extracted from plasma (Suzuki et al. 2011). They concluded that plasma was better than blood mononuclear cells for the detection of this virus. 
Leukocytes were not isolated as a source of viral DNA in the current study because it is a time-consuming process and increases the chance of cross-contamination.

To escape digestion by endonucleases, viral DNA in the blood exists as circulating intact virons (Bloom et al. 1987), although the presence of small-size naked Epstein-Barr virus DNA fragments has been demonstrated in plasma (Chan et al. 2003). Because macrophages are the targets of AMDV infection and sequestration (Bloom et al. 1994; Best and Bloom 2006), the source of AMDV DNA in the circulating blood is likely intact virions released from apoptotic leukocytes as well as virion-antibody complexes which is a characteristic of AMDV infection (Bloom et al. 1994). It has been postulated that only a small and unpredictable fraction of leukocytes containing virus particles are lysed and constitute the source of viral DNA which can be extracted from serum or plasma (Stevens et al. 2001). This phenomenon along with the fact that AMDV replication peaks at around 10 days post-infection in mink, followed by a decrease in viral replication of up to several orders of magnitude over the succeeding few weeks (Bloom et al. 1994) could be the reason for the finding that neither of the PCR methods in the current study detected AMDV DNA in $40.6 \%$ and $49.4 \%$ of the blood preparations. This is not surprising because animals used in the current study were sampled 4 and 16 months after inoculation, and were expected to have low AMDV copy number in their bloodstream by that time. Shortlived or irregular viremia have been reported in mink several weeks after infection with AMDV (Jackson et al. 1996; Jensen et al. 2014).

The most striking result of this study was the observation that all samples that were tested positive by DB were also positive by the Klentaq, and more than $50 \%$ of the samples that were negative using DB became positive or inconclusive by the Klentaq in 
various blood preparations. There are two possible reasons for this observation. First, the loss of AMDV DNA occurring during the DNA extraction process is inevitable. DNA losses during extraction by commercial kits varies widely and is influenced by the type of extraction kit and the source of tissue (Fredricks et al. 2005; Queipo-Ortuño et al. 2008; Cai et al. 2011). The amount of DNA lost is often large, for instance $21.75 \%$ to $60.56 \%$ (Kemp et al. 2014), $45.1 \%$ to $99.5 \%$ (Barta et al. 2014) and $57.5 \%$ to $100 \%$ (Mumy and Findlay 2004). It could be hypothesized that the low amounts of AMDV DNA in the circulation of most chronically infected mink in the current study, in addition to the losses during the extraction process, resulted in a low viral copy number and PCR failure. The second reason for the greater PCR success rate in direct amplification could be the failure of the DNA extraction kit to remove all PCR inhibitors along with the use of inhibitorsensitive Taq DNA polymerase. Co-extraction of PCR inhibitors by commercial DNA extraction kits has been observed in other studies, which caused PCR amplification failure when inhibitor-sensitive Taq DNA polymerases were used (reviewed in Alaeddini 2012; Kramvis et al. 1996; Klein et al. 1997), whereas the use of inhibitor-resistant DNA polymerases, such as Klentaq, improved PCR success rate (Monroe et al. 2013).

The differences observed between the three methods of blood preparations for PCR success rate by the Klentaq is of practical importance for detecting AMDV DNA in live animals and there is no published information to compare these results with. The discrepancy between the results of direct PCR amplifications by the Klentaq in different blood preparations could be the manifestation of differences in viral load as well as the type and the amount of inhibitors in each source. The three volumes of 1:3 diluted whole blood $(0.5,1.0$ and $2.0 \mu \mathrm{L})$ used in $25 \mu \mathrm{L}$ total PCR reaction volume corresponded to 
$0.5 \%, 1 \%$ and $2 \%$ of the original whole blood in the PCR reaction mixture. The use of 4.0 $\mu \mathrm{L}$ and $5.7 \mu \mathrm{L}$ of the $1: 3$ diluted whole blood and $2.0 \mu \mathrm{L}$ of $1: 2$ dilution, corresponding to $4 \%, 5.7 \%$ and $2.7 \%$ whole blood, respectively, were tested and caused gelling of some PCR reactions and failure of the test. The maximum volume of whole blood which was successfully used in the current experiment was considerably lower than the $25 \%$ previously suggested for the Klentaq (Zhang et al. 2010). In the current experiment, the amounts of undiluted serum and plasma in the PCR cocktail were $2 \%, 4 \%$ and $8 \%$ of the PCR reaction mixture.

The observed differences in PCR success rate among tissues by extracted DNA and direct amplification by the Klentaq were likely the result of variable amounts of viral DNA present in each tissue (Jensen et al. 2014), as well as the type and the amount of PCR inhibitors. PCR success rates in all tissues were greater than those in the blood preparations by both PCR methods, which is attributable to the limited AMDV replication in chronically infected mink (Bloom et al. 1994; Best and Bloom 2006). The two PCR methods were comparable for bone marrow and lymph nodes, likely because of their high virus content, implying that direct viral DNA detection is not advantageous over DNA extraction when viral load is high in a sample and some DNA losses during the extraction step does not have a major effect on the results. The greatest number of negative PCR results by both PCR methods was observed in the liver (40\%), which is consistent with the result of the previous experiment where AMDV was tested in the same seven organs of mink 10 days post-inoculation and liver showed the highest negative PCR results (35.7\%) (Farid et al. 2015).

More spleen samples were tested than other tissues because of its relatively large 
size, ease of sampling and the fact that it is one of the sites of AMDV replication and sequestration (Bloom et al. 1994), and that AMDV DNA can be detected in the spleen more often than in non-lymphoid organs (Jensen et al. 2014, Farid et al. 2015). The use of Klentaq increased the rate of PCR success in the spleen compared with DNA extracted by DB in the current study $(73.4 \%$ vs $44.1 \%)$ and is thus a preferred method of AMDV DNA detection in this tissue taken from mink cadavers.

Blood and tissues carry the DNA of infectious agents in addition to that of the host, making it difficult to quantify viral DNA load separately from genomic DNA by a spectrophotometer. For this reason, three volumes of blood preparations and tissue homogenates were used in this study. Similarities in PCR success rate for different volumes of spleen homogenates was possibly due to the negative effect of PCR inhibitors, which negated the increased amount of viral DNA in the PCR reaction as sample volume increased. The level of PCR inhibitors was possibly lower in plasma and serum than in the whole blood, which resulted in sharp increases in both positive and inconclusive PCR results when $2.0 \mu \mathrm{L}$ of plasma and serum were used. It can be concluded that $2.0 \mu \mathrm{L}$ of blood preparations was the best for the direct detection of AMDV DNA by the Klentaq in chronically infected mink. Although $4 \mu \mathrm{L}$ of 1:3 diluted whole blood caused PCR failure in some samples, this input volume was not tested for serum, plasma or tissue homogenates and requires further investigation.

\section{Conclusions}

Compared with extracted DNA from plasma and seven organs by a commercial nucleic acid extraction kit, Omni Klentaq-LA significantly increased the number of PCR positive 
samples in whole blood, plasma, serum, spleen and small intestine. The use of Klentaq reduces the cost of $\mathrm{PCR}$ tests, lowers the risk of sample contamination and eliminates viral DNA losses during DNA extraction. The latter is important in chronically infected mink which have low virus copy number in the bloodstream. Direct viral DNA detection by the Klentaq requires lower amounts of blood compared with DNA extraction methods, which is an important factor in mink where sampling is performed by toe-nail clipping. Although not tested in this study, Klentaq can be used for accurate measure of AMDV DNA copy number in blood, serum or plasma by quantitative real-time PCR. Such a measurement would be an accurate indicator of replication activity of AMDV in an individual, and can be used as a tool to identify mink which can suppress viral replication and can possibly tolerate the infection.

\section{Acknowledgments}

We would like to acknowledge Irshad Hussein and Irin Arju for their assistance in mink inoculation and sampling. Financial support from mink industry organizations (Canada Mink Breeders Association, Nova Scotia Mink Breeders Association, Fur Farmers of Canada Marketing Association, American Legend Cooperatives, North American Fur Auctions, American Mink Council, American Mink Farmers Research Foundation, Fur Commission USA), Agriculture and Agri-Food Canada through the CARD Councils of Ontario, British Columbia and Nova Scotia (Agri-Futures NS), Atlantic Innovation Fund of Atlantic Opportunity Agency and the Technology Development Program of the Nova Scotia Department of Agriculture is gratefully acknowledged.

\section{References}


Aasted, B., Alexandersen, S., and Christensen, J., 1998. Vaccination with Aleutian mink disease parvovirus (AMDV) capsid proteins enhances disease, while vaccination with the major non-structural AMDV protein causes partial protection from disease. Vaccine. 16: 1158-1165.

Abu Al-Soud, W., and Râdström, P. 1998. Capacity of nine thermostable DNA polymerases to mediate DNA amplification in the presence of PCR-inhibiting samples. Appl Environ Microbiol. 64:3748-3753.

Alaeddini, R. 2012. Forensic implications of PCR inhibition - A review. Forensic Sci Int Genet. 6:297-305. doi: 10.1016/j.fsigen.2011.08.006.

Barta, J.L., Monroe, C., Teisberg, J.E., Winters, M., Flanigan, K., and Kempa, B.M. 2014. One of the key characteristics of ancient DNA, low copy number, may be a product of its extraction. J. Archaeological Sci. 46:281-289.

Best, S.M., and Bloom, M.E. 2006. Aleutian mink disease parvovirus, In Parvoviruses. Edited by J. Kerr, S. Cotmore, M.E. Bloom. Hodder Arnold Publication, London, UK., pp 457-471.

Bloom, M.E., Race, R.E., Hadlow, W.J., and Chesebro, B., 1975. Aleutian disease of mink: the antibody response of sapphire and pastel mink to Aleutian disease virus. J. Immunol. 115:1034-1037. 
Bloom, M.E., Race, R.E., and Wolfinbarger, J.B. 1987. Analysis of Aleutian disease of mink parvovirus infection using strand-specific hybridization probes. Intervirology. 27:102111.

Bloom M.E., Kanno, H., Mori, S., and Wolfinbarger, J.B., 1994. Aleutian mink disease: puzzles and paradigms. Infect. Agents Dis. 3:279-301.

Broll, S., and Alexandersen, S., 1996. Investigation of the pathogenesis of transplacental transmission of Aleutian mink disease parvovirus in experimentally infected mink. J. Virol. 70:1455-1466.

Cai, H., Gu, X., Scanlan, M.S., and Lively C.R. 2011. Development of a quantitative PCR assay for residual mouse DNA and comparison of four sample purification methods for DNA isolation. J. Pharm. Biomed. Anal. 55:71-77. doi: 10.1016/j.jpba.2011.01.010.

Castelruiz, Y., Blixenkrone-Moller, M., and Aasted, B., 2005. DNA vaccination with the Aleutian mink disease virus NS1 gene confer partial protection against disease. Vaccine. 23:1225-1231.

Chan, K.C., Zhang, J., Chan, A.T., Lei, K.I., Leung, S.F., Chan, L.Y., Chow, K.C., and Lo, Y.M. 2003. Molecular characterization of circulating EBV DNA in the plasma of nasopharyngeal carcinoma and lymphoma patients. Cancer Res. 63:2028-2032. 
Chen, X.Y., Hou, P.F., Bi, J., and Ying, C.M. 2014. Detection of human cytomegalovirus DNA in various blood components after liver transplantation. Braz. J. Med. Biol. Res. 47:340-344.

Cho, H.J., and Ingram, D.G., 1973. Antigen and antibody in Aleutian disease in mink. IIThe reaction of antibody with the Aleutian disease agent using immunodiffusion and immunoelectrophoresis. Can. J. Comp. Med., 37: 217-223.

Cotmore, S.F., Agbandje-McKenna, M., Chiorini, J.A., Mukha, D.V., Pintel, D.J. Qiu, J., et al., 2014. The family Parvoviridae. Arch. Virol. 159:1239-1247.

Deback, C., Fillet, A.M., Dhedin, N., Barrou, B., Varnous, S., Najioullah, F., Bricaire, F., and Agut, H. 2007. Monitoring of human cytomegalovirus infection in immunosuppressed patients using real-time PCR on whole blood. J. Clin. Virol. 40:173-179.

Dyer, N.W., Ching, B., and Bloom, M.E. 2000. Nonsuppurative meningoencephalitis associated with Aleutian mink disease parvovirus infection in ranch mink. J. Vet. Diagn. Invest. 12:159-162.

Eilert, K.D., and Foran, D.R. 2009. Polymerase resistance to polymerase chain reaction inhibitors in bone. J. Forensic Sci. 54:1001-1007. doi: 10.1111/j.1556-4029.2009.01116.x. 
Farid, A.H. 2013. Aleutian mink disease virus in furbearing mammals in Nova Scotia, Canada. Acta. Veterin. Scand. 55,10. doi:10.1186/1751-0147-55-10

Farid, A.H., Zillig, M.L., Finley, G.G., and Smith, G.C., 2012. Prevalence of the Aleutian mink disease virus infection in Nova Scotia, Canada. Prevent. Vet. Med. 106:332-338.

Farid, A.H., Hussain, I., and Arju, I. 2015. Detection of Aleutian mink disease virus DNA and anti-viral antibodies in American mink (Neovison vison) 10 days post-inoculation. J. Vet. Diag. Invest. 27:287-294. doi: 10.1177/1040638715580982

Fredricks, D.N., Smith, C., and Meier, A. 2005. Comparison of six DNA extraction methods for recovery of fungal DNA as assessed by quantitative PCR. J. Clin. Microbiol. 43:51225128.

Frickhofen, N., and Young, N.S. 1991. A rapid method of sample preparation for detection of DNA viruses in human serum by polymerase chain reaction. J. Virol. Methods. 35:6572.

Hadlow, W.J., Race, R.E., and Kennedy, R.C. 1985. Temporal replication of the Pullman strain of Aleutian disease virus in royal pastel mink. J. Virol. 55:853-856.

Ito, Y., Suzuki, M., Kawada, J.I., and Kimura, H. 2016. Diagnostic values for the viral load in peripheral blood mononuclear cells of patients with chronic active Epstein-Barr virus 
disease. J. Infect. Chemother. 22(4):268-271. doi:10.1016/j.jiac.2015.11.002

Jackson, M.K., Ellis, L.C., Morrey, J.D., and Barnard, D.L., 1992. Early detection of Aleutian disease virus in mink by polymerase chain reaction. Norw. J. Agricul. Sci. (Suppl. 9). $383-387$.

Jackson, M.K., Ellis, L.C., Morrey, J.D., Li, Z.Z., and Barnard, D.L. 1996. Progression of Aleutian disease in natural and experimentally induced infections of mink. Am. J. Vet. Res. 57:1753-1758.

Jensen, T.H., Hammer, A.S., and Chriél, M., 2014. Monitoring chronic infection with a field strain of Aleutian mink disease virus. Vet. Microbiol. 168:420-427.

Kemp, B.M., Winters, M., Monroe, C., and Barta, J.L. 2014. How much DNA is lost? Measuring DNA loss of short-tandem-repeat length fragments targeted by the PowerPlex $16 \circledast$ system using the Qiagen MinElute Purification Kit. Hum. Biol. 86:313-329.

Kermekchiev, M.B., Kirilova, L.I., Vail, E.E., and Barnes, W.M. 2009. Mutants of Taq DNA polymerase resistant to PCR inhibitors allow DNA amplification from whole blood and crude soil samples. Nucleic Acids Res. 37(5): e40. doi: 10.1093/nar/gkn1055.

Klein, A., Barsuk, R., Dagan, S., Nusbaum, O., Shouval, D., and Galun, E. 1997. Comparison of methods for extraction of nucleic acid from hemolytic serum for PCR 
amplification of hepatitis B virus DNA sequences. J. Clin. Microbiol. 35:1897-1899.

Kramvis, A., Bukofzer, S., and Kew, M.C. 1996. Comparison of hepatitis B virus DNA extractions from serum by the QIAamp blood kit, GeneReleaser, and the phenolchloroform method. J. Clin. Microbiol. 34:2731-2733.

Miura, M., Tanigawa, C., Fujii, Y., and Kaneko, S. 2013. Comparison of six commerciallyavailable DNA polymerases for direct PCR. Rev. Inst. Med. Trop. Sao Paulo. 5540155406. doi: 10.1590/S0036-46652013000600005.

Monroe, C., Grier, C., and Kemp, B.M. 2013. Evaluating the efficacy of various thermostable polymerases against co-extracted PCR inhibitors in ancient DNA samples. Forensic Sci Int. 228:142-153. doi: 10.1016/j.forsciint.2013.02.029.

Mumy, K.L., and Findlay, R.H. 2004. Convenient determination of DNA extraction efficiency using an external DNA recovery standard and quantitative-competitive PCR. J. Microbiol. Methods. 57:259-268.

Oie, K.L, Durran, G., Wolfinbarger, J.B., Martin, D., Costello, F., Perryman, S., Hogan,D., Hadlow, W.J., and Bloom, M.E. 1996. The relationship between capsid protein (VP2) sequence and pathogenicity of Aleutian mink disease parvovirus (ADV): A possible role for raccoons in the transmission of ADV infections. J. Virol. 70:852-861 
Queipo-Ortuño, M.I., Tena, F., Colmenero, J.D., and Morata, P. 2008. Comparison of seven commercial DNA extraction kits for the recovery of Brucella DNA from spiked human serum samples using real-time PCR. Eur. J. Clin. Microbiol. Infect. Dis. 27:109114. doi 10.1007/s10096-007-0409-y

Rådström, P., Knutsson, R., Wolffs, P., Lövenklev, M., and Löfström, C. 2004. Pre-PCR processing: strategies to generate PCR-compatible samples. Mol. Biotechnol. 26:133-46.

Ramroodi, N., Sanadgol, N., Ganjali, Z., Niazi, A.A., Sarabandi, V., and Moghtaderi, A. 2013. Monitoring of active human herpes virus 6 infection in Iranian patients with different subtypes of multiple sclerosis. J. Pathog. 2013:194932. doi: 10.1155/2013/194932.

Reichert, M., and Kostro, K. 2014. Effect of persistent infection of mink with Aleutian mink disease virus on reproductive failure. Bull. Vet. Inst. Pulawy 58:369-373, doi: 10.2478/bvip2014-0057

Shipley, M.A., Koehler, J.W., Kulesh, D.A., and Minogue, T.D. 2012. Comparison of nucleic acid extraction platforms for detection of select biothreat agents for use in clinical resource limited settings. J. Microbiol. Meth. 91:179-183. doi: 10.1016/j.mimet.2012.06.008.

Stevens, S.J., Pronk, I., and Middeldorp, J.M. 2001. Toward standardization of EpsteinBarr virus DNA load monitoring: unfractionated whole blood as preferred clinical specimen. 
J. Clin. Microbiol. 39:1211-1216.

Suzuki, R., Yamaguchi, M., Izutsu, K., Yamamoto, G., Takada, K., Harabuchi, Y., et al., 2011. Prospective measurement of Epstein-Barr virus-DNA in plasma and peripheral blood mononuclear cells of extranodal NK/T-cell lymphoma, nasal type. Blood. 118:60186022. doi: 10.1182/blood-2011-05-354142.

Trombley Hall, A., Zovanyi, A.M., Christensen, D.R., Koehler, J.W., and Minogue, T.D. 2013. Evaluation of inhibitor-resistant real-time PCR methods for diagnostics in clinical and environmental samples. PLoS One. 8(9): e73845. doi: 10.1371/journal.pone.0073845. eCollection 2013.

Yang, Y.G., Kim, J.Y., Song, Y.H., and Kim, D.S. 2007. A novel buffer system, AnyDirect, can improve polymerase chain reaction from whole blood without DNA isolation. Clin. Chim. Acta. 380:112-117.

Zhang, Z., Kermekchiev, M.B., and Barnes, W.M. 2010. Direct DNA amplification from crude clinical samples using a PCR enhancer cocktail and novel mutants of Taq. J. Mol. Diagn. 12:152-161. doi: 10.2353/jmoldx.2010.090070. 
Table 1: Joint distribution of PCR amplification results of plasma, serum and whole blood using direct AMDV DNA amplification by Omni Klentaq and DNA extracted by Dynabeads from plasma

\begin{tabular}{|c|c|c|c|c|c|c|}
\hline \multirow[b]{2}{*}{ Source } & \multirow{2}{*}{$\begin{array}{c}\text { Omni Klentaq } \\
\text { PCR results }\end{array}$} & \multicolumn{3}{|c|}{ Dynabeads } & . & \multirow{2}{*}{$\begin{array}{l}\text { Likelihood } \\
\text { Ratio } x^{2}\end{array}$} \\
\hline & & Positive & Inconclusive & Negative & Total & \\
\hline \multirow[t]{4}{*}{ Plasma } & Positive & 16 & 4 & 71 & 91 & $\kappa^{2}=27.9$ \\
\hline & Inconclusive & 0 & 0 & 19 & 19 & $P<0.0001$ \\
\hline & Negative & 0 & 1 & 76 & 77 & \\
\hline & Total & 16 & 5 & 166 & 187 & \\
\hline \multirow[t]{4}{*}{ Serum } & Positive & 15 & 4 & 60 & 79 & $\kappa^{2}=29.5$ \\
\hline & Inconclusive & 0 & 1 & 14 & 15 & $P=0.0001$ \\
\hline & Negative & 1 & 0 & 93 & 94 & \\
\hline & Total & 16 & 5 & 167 & 188 & \\
\hline \multirow{4}{*}{$\begin{array}{l}\text { Whole } \\
\text { blood }\end{array}$} & Positive & 16 & 2 & 47 & 65 & $\kappa^{2}=37.2$ \\
\hline & Inconclusive & 0 & 1 & 37 & 38 & $P<0.0001$ \\
\hline & Negative & 0 & 2 & 83 & 85 & \\
\hline & Total & 16 & 5 & 167 & 188 & \\
\hline
\end{tabular}

"PCR results of DNA isolated from plasma were compared with Omni Klentaq results obtained on plasma, serum and whole blood. 
Table 2: Pairwise comparison of direct PCR amplification of AMDV DNA by Omni Klentaq in plasma, serum and whole blood

\begin{tabular}{|c|c|c|c|c|c|c|}
\hline \multirow{6}{*}{ Plasma } & \multicolumn{5}{|c|}{ Serum } & \multirow{2}{*}{$\begin{array}{l}\text { Likelihood } \\
\text { Ratio } x^{2}\end{array}$} \\
\hline & & Positive & Inconclusive & Negative & Total & \\
\hline & Positive & 54 & 6 & 31 & 91 & \\
\hline & Inconclusive & 11 & 2 & 6 & 19 & $\kappa^{2}=36.7$ \\
\hline & Negative & 13 & 7 & 57 & 77 & $P<0.0001$ \\
\hline & Total & 78 & 15 & 94 & 187 & \\
\hline \multicolumn{7}{|c|}{ Whole blood } \\
\hline \multirow{5}{*}{ Plasma } & & Positive & Inconclusive & Negative & Total & \multirow{5}{*}{$\begin{array}{c}x^{2}=30.2 \\
P<0.0001\end{array}$} \\
\hline & Positive & 32 & 7 & 52 & 91 & \\
\hline & Inconclusive & 4 & 3 & 12 & 19 & \\
\hline & Negative & 29 & 28 & 20 & 77 & \\
\hline & Total & 65 & 38 & 84 & 187 & \\
\hline \multicolumn{7}{|c|}{ Whole blood } \\
\hline \multirow{5}{*}{ Serum } & & Positive & Inconclusive & Negative & Total & \multirow{5}{*}{$\begin{array}{l}\kappa^{2}=8.86 \\
P=0.065\end{array}$} \\
\hline & Positive & 34 & 9 & 36 & 79 & \\
\hline & Inconclusive & 5 & 3 & 7 & 15 & \\
\hline & Negative & 26 & 26 & 42 & 94 & \\
\hline & Total & 65 & 38 & 85 & 188 & \\
\hline
\end{tabular}


Table 3: Joint distribution of PCR amplification results of seven tissue homogenates using direct AMDV DNA amplification by Omni Klentaq and DNA extracted by Dynabeads

\begin{tabular}{|c|c|c|c|c|c|c|}
\hline \multirow{2}{*}{ Tissue } & \multirow[b]{2}{*}{ Dynabeads } & \multicolumn{3}{|c|}{ Omni Klentaq } & \multirow{2}{*}{ Total } & \multirow{2}{*}{$\begin{array}{l}\text { Likelihood } \\
\text { Ratio } \kappa^{2}\end{array}$} \\
\hline & & Positive & Inconclusive & Negative & & \\
\hline \multirow{4}{*}{ Spleen } & Positive & 78 & 3 & 2 & 83 & $\kappa^{2}=54.3$ \\
\hline & Inconclusive & 13 & 0 & 0 & 13 & $P=<0.000$ \\
\hline & Negative & 47 & 13 & 32 & 92 & \\
\hline & Total & 138 & 16 & 34 & 188 & \\
\hline \multirow[t]{4}{*}{ Bone marrow } & Positive & 15 & 0 & 0 & 15 & $\kappa^{2}=4.1$ \\
\hline & Inconclusive & 2 & 0 & 0 & 2 & $P=0.12$ \\
\hline & Negative & 2 & 1 & 0 & 3 & \\
\hline & Total & 19 & 1 & 0 & 20 & \\
\hline \multirow[t]{3}{*}{ Small intestine } & Positive ${ }^{*}$ & 7 & 0 & 0 & 7 & $\kappa^{2}=7.95$ \\
\hline & Negative & 6 & 2 & 5 & 13 & $P=0.02$ \\
\hline & Total & 13 & 2 & 5 & 20 & \\
\hline \multirow[t]{3}{*}{ Kidneys } & Positive ${ }^{*}$ & 12 & 0 & 1 & 13 & $\kappa^{2}=13.4$ \\
\hline & Negative & 1 & 1 & 5 & 7 & $P=0.001$ \\
\hline & Total & 13 & 1 & 6 & 20 & \\
\hline \multirow[t]{3}{*}{ Lymph node } & Positive* & 13 & 1 & 1 & 15 & $\kappa^{2}=4.7$ \\
\hline & Negative & 0 & 0 & 1 & 1 & $P=0.10$ \\
\hline & Total & 13 & 1 & 2 & 16 & \\
\hline \multirow[t]{3}{*}{ Liver } & Positive ${ }^{*}$ & 11 & 0 & 0 & 11 & $\kappa^{2}=27.5$ \\
\hline & Negative & 0 & 1 & 8 & 9 & $P=0.000$ \\
\hline & Total & 11 & 1 & 8 & 20 & \\
\hline \multirow[t]{3}{*}{ Lungs } & Positive $^{*}$ & 8 & 0 & 0 & 8 & $\kappa^{2}=3.41$ \\
\hline & Negative & 9 & 0 & 3 & 12 & $P=0.06$ \\
\hline & Total & 17 & 0 & 3 & 20 & \\
\hline
\end{tabular}

"There was no inconclusive PCR result for extracted DNA for this organ 
Table 4. Percentage of PCR positive and inconclusive results in $0.5,1.0$ and $2.0 \mu \mathrm{L}$ plasma, serum, whole blood and spleen homogenate directly tested by Omni Klentaq in PCR reactions and pairwise comparison of combined positive and inconclusive results

\begin{tabular}{|c|c|c|c|c|c|c|c|c|c|c|}
\hline \multirow[t]{3}{*}{ Sample } & \multicolumn{3}{|c|}{ PCR Positive } & \multicolumn{3}{|c|}{ PCR Inconclusive } & \multirow{3}{*}{$\begin{array}{c}\text { Number } \\
\text { of } \\
\text { samples }\end{array}$} & \multicolumn{2}{|c|}{ Probability } & \multirow{3}{*}{$\begin{array}{l}0.5 \mathrm{vs} \\
1.0 \mu \mathrm{L}\end{array}$} \\
\hline & 0.5 & 1.0 & 2.0 & 0.5 & 1.0 & 2.0 & & 0.5 vs & 0.5 vs & \\
\hline & $\mu \mathrm{L}$ & $\mu \mathrm{L}$ & $\mu \mathrm{L}$ & $\mu \mathrm{L}$ & $\mu \mathrm{L}$ & $\mu \mathrm{L}$ & & $1.0 \mu \mathrm{L}$ & $1.0 \mu \mathrm{L}$ & \\
\hline Plasma & 7.5 & 10.2 & 30.5 & 11.2 & 13.4 & 21.4 & 187 & 0.183 & 0.000 & 0.000 \\
\hline Serum & 9.7 & 8.6 & 21.8 & 16.1 & 16.1 & 20.2 & 188 & 0.828 & 0.001 & 0.000 \\
\hline Whole blood & 16.3 & 15.7 & 16.2 & 11.9 & 28.1 & 36.2 & 185 & 0.005 & 0.001 & 0.689 \\
\hline Spleen & 38.4 & 40.5 & 39.0 & 12.0 & 13.4 & 8.9 & 188 & $* *$ & $* *$ & $* *$ \\
\hline
\end{tabular}

"Probability of difference between sample volumes using Mann-Whitney test when

Kruskal-Wallis ANOVA was significant. Probabilities smaller than $\alpha=0.05 / 3=0.017$

(Bonferroni correction) are significant.

Differences were not significant using Kruskal-Wallis ANOVA. 